\title{
Bağlamın Etkisinde Şekillenen Örgütler Arası Bağların Finansal Performans Üzerindeki Etkileri: Türkiye'deki İşletme Grupları Örneği ${ }^{1}$
}

\begin{abstract}
Selcen SARI ${ }^{2}$
ÖZ: Bu araştırmanın amacı, gelişmekte olan ülke bağlamının etkisi ile şekillenen bă̆ yapılarının aktör olarak örgütlerin finansal performanslarını etkileyip etkilemediğini ortaya koymaktır. Bu ilişki, Borsa İstanbul'da koteli ve bir işletme grubuna bağll işletmelerden oluşan örneklem üzerinde analiz edilmiştir. Toplamda 15 işletme grubuna ait 74 bağlı işletmenin verileri ile yürütülen analizler sonucunda, güçlü bağlardan oluşan ă̆ yapısının finansal performans üzerindeki etkisine dair istatistiksel olarak anlamlı ilişkiler gözlenmemiştir.
\end{abstract}

Anahtar Kelimeler: Sosyal Sermaye, Güçlü Bağlar, İşletme Grupları, Finansal Performans

JEL Kodları: L21, L25, M10, M19

\section{The Effect of Interorganizational Ties That Are Formed Under Influence of the Context on Financial Performance: Evidence from Turkish Business Groups}

\begin{abstract}
The aim of this research is to examine whether the type of ties that are formed under the influence of developing country context can affect firms' financial performances. This relation is analyzed on a sample that contains affiliates of various business groups which are listed in Borsa Istanbul. The findings of the analysis conducted with data of 74 affiliates of 15 business groups suggest no statistically significant effect of networks formed with strong ties on financial performance.
\end{abstract}

Key Words: Social Capital, Strong Ties, Business Groups, Financial Performance JEL Codes: L21, L25, M10, M19

\footnotetext{
${ }^{1}$ Bu çalışma Selcen SARI’ya ait “Sosyal Sermaye İle Finansal Performans Arasındaki İlişki ve Bu ilişkide Uluslararası Çeşitlenmenin Aracılık Etkisi: Türkiye'deki İşletme Grupları Örneği” başlıklı doktora tezinden üretilmiştir.

${ }^{2}$ Öğr. Gör. Dr. Karadeniz Teknik Üniversitesi, Trabzon MYO, selcensari@ktu.edu.tr.
} 


\section{Giris}

Birçok farklı disiplin tarafından ele alınan ve son yılların popüler konularından bir tanesi olan sosyal sermaye "karşılıklı tanışıklık ve bilme halinden kaynaklanan az ya da çok kurumsallaşmış ilişkilerden oluşan dayanıklı ağlara sahip olunmasıyla elde edilen fiili ya da potansiyel kaynakların toplamıdır" şeklinde tanımlanmaktadır (Bourdieu, 2002: 286). Sosyal sermaye, fiziki sermaye ve beşeri sermayeyi tamamlayarak yokluğunda başarılamayacak bazı sonuçları mümkün kılmaktadır (Coleman, 1988a: 98). Böylelikle örneğin, eşit düzeyde fiziki sermayeye sahip olmalarına rağmen firmaların performans düzeylerindeki farklılığı açıklamak bir noktaya kadar mümkün olabilmektedir.

Sargut (2006) sosyal sermayenin, ağ düzenekleri içinde yerleşik ilişkileri kaynak olarak kullandığ 1 için sosyal sermaye araştırmalarında ağ düzeneği kuramlarının göz önünde bulundurulması gerektiğini vurgulamaktadır. Ağlar olmadan yerleşik kaynakları ele geçirmenin mümkün olmamaktadır (Lin, 2005: 11). O halde sosyal sermayenin kullanılabilmesi için ağlar bir araçtır. A $\breve{g}$ ise, aktörleri birbirine bağlayan "bağların" bir araya gelmesi ile oluşmaktadır.

Bir örgütün sahip olduğu ağın farklı boyutları olmakla birlikte, bu boyutlardan bir tanesi de bağların yapısal konfigürasyonudur (Gulati ve diğerleri, 2002: 288-292). Yazın incelendiği takdirde güçlü bağlar, zayıf bağlar, köprü kuran bağlar, kaynaştıran bağlar gibi farklı tür bağ yapılarından bahsedildiği göze çarpmaktadır. Farklı yapılardaki bağların firmaya farklı getirileri olmaktadır (Baker, 1990). Buradaki önemli nokta, bağlamın da etkisini dikkate alarak fayda sağlayan bağ yapısını ortaya koyabilmektir. Çünkü aktörler arası kurulan bağlar ve bu bağlar aracılığı ile oluşan ağ yapıları durağan değildirler. Zaman içerisinde değişebilen ve nitelikleri farklılaşabilen ilişkiler, elde edilen kazanımları da farklılaştırabilmektedir.

Bu sebeple, bu çalışmanın temel amacı, araştırmanın yürütüldüğü gelişmekte olan ülke bağlamının özellikleri dikkate alınarak, oluşan bağ yapılarının aktör olarak örgütlerin finansal performansını etkileyip etkilemediğini açığa çıkartmaktır. Böylelikle sosyal sermaye yazınına yapılacak katkının da ötesinde gelişmekte olan ülke bağlamında, bağlamın kendine has özellikleri ile şekillenebilen bağ yapılarının irdelenebilmesi mümkün olabilecektir. $\mathrm{Bu}$ sayede aktörlerin etraflarındaki ağ yapılarını farklı bir açıdan değerlendirebilmeleri sağlanarak, gerekli hallerde bu ağ yapılarını kendilerine avantaj yaratabilecek şekilde yönetebilmelerine katkı sağlanabilecektir.

Çalışmanın ikinci bölümünde, ilgili yazın gözden geçirilerek kavramsal bir çerçeve oluşturulmakta ve kullanılan araştırma modeli ile araştırma hipotezleri sunulmaktadır. Üçüncü bölümde araştırmanın tasarımı ve bulguları sunulmakta, çalışma tartışma ve sonuç bölümü ile sonlanmaktadır. 


\section{Kavramsal Çerçeve ve Araştırma Modeli}

Örgütler de bireyler gibi çevreleri ile ilişkiler geliştirmekte ve bu ilişkileri aracılığı ile ağlara dâhil olabilmektedirler. Yer aldıkları bu ağlar sayesinde de çevrelerindeki firsatlara ve kaynaklara erişme imkânı yakalamaktadırlar. Örgütün içinde yer aldığı bu ağ, karşılaşabileceği firsatları farklılaştırabilmekteyken, ağ içerisinde kurduğu bağların türü fırsatların ne kadarına ulaşabileceğini de değiştirebilmektedir (Uzzi, 1996: 675).

Bir bağ ya güçlü bir bağdır, ya zayıftır ya da var olmayan bir bağdır (Granovetter, 1973: 1361). Bağın gücünün ise dört tane belirleyicisi vardır (Granovetter, 1973: 1361): (i) birlikte geçirilen zaman, (ii) ilişki içindeki taraflar arasındaki duygusal yoğunluk, (iii) samimiyet ve (iv) karşılıklılık. Bu dört değişkenin fazlalığı güçlü bağları işaret ederken, azlığı zayıf bağları ortaya koymaktadır. Granovetter (1973, 1983) çalışmalarında zayıf bağların gücüne dikkat çekmektedir. Bu görüşe göre sosyal sermayeyi oluşturan ağ yapısı kaynağı zayıf bağlardır ve bu tür bağlar sayesinde oluşan ağ, birbiri ile aynı bilgiyi sağlamayan farklı kaynaklardan firmanın bilgi almasına ve daha büyük bir çevrede yerleşik kaynaklara ulaşmasına yardımcı olmaktadır (Koka ve Prescott, 2002: 800; Kraatz, 1998: 623). Zayıf bağların gücü yaklaşımına göre birbirine benzer aktörler arasında güçlü bağlar oluşmaktadır ve bu nedenle güçlü bağlar ile bağlı olduğumuz aktörler benzer düşüncelere ve benzer (ya da tekrarlayan) bilgiye sahip aktörler olduklarından güçlü bağlar yeni ya da özgün bilgi üretmekten yoksundurlar (Granovetter, 1973: 1362).

Aynı sayıda bağa sahip iki firmadan, daha faklı stratejik gruplarla bağ kurabilen firma daha çeşitli, daha kapsamlı ve birbirini tekrar etmeyen bilgiye ulaşabilmektedir (Koka ve Prescott, 2002: 800). Daha farklı aktörlere doğrudan ulaşmayı sağlayan böyle bir ağdaki bilginin sağladığı faydanın kalitesi de artmaktadır (Burt, 1997: 342). Bu yaklaşıma göre farklı bilginin kaynağı zayıf bağlar ile aktörü homojen olmayan ve birçok ağa bağlayan yapılardır.

$\mathrm{Bu}$ konudaki diğer görüş ise aktörler arasında kurulan güçlü bağları öne çıkarmaktadır. Güçlü bağların üç tane belirleyici özelliği vardır: (i)sık etkileşim, (ii)samimiyet ve (iii) birlikte geçirilen zamanın çokluğu ya da uzun bir geçmişe sahip olmak (Krackhardt, 1992: 218-219). Etkileşim sıklığı bilgi paylaşımı firsatı yaratırken aynı zamanda kimisi gizli kalması gereken bazı bilgilerin de paylaşılması imkânı yaratabilmekte; samimiyet, diğerlerine zarar verecek herhangi bir harekette bulunmanın önüne geçebilmekte ve birlikte geçirilen zamanın uzunluğu her bir aktörün, paylaşılan bilgiyi ne şekilde kullanacağının tahmin edilebilmesine olanak sağlamaktadır (Krackhardt, 1992: 219). Bu parçaların her biri güvenin oluşmasını sağlarken, parçalardan herhangi birinin eksikliği güvenin kırılmasına sebep olmaktadır (Krackhardt, 1992: 219).

Güçlü bağlar sayesinde oluşan güven taraflar arasında daha değerli ve örtük bilginin paylaşılmasına imkân sağlarken, bu türden bilgiye erişim hem firmanın 
farklı bilgi kaynakları arama ve izleme maliyetlerini azaltmakta hem de karar verme sürecini hızlandırmaktadır (Uzzi, 1996: 681-682). Daha hızlı karar alabilen firmanın çevredeki değişikliklere daha hızlı tepki vermesi, daha erken önlem alabilmesi ve böylelikle kendini koruyabilmesi veya firsatlardan herkesten önce haberdar olması ve bu fırsatları değerlendirebilmesi mümkün olabileceği gibi kaynak arama ve izleme maliyetlerinin azalması ile işlem maliyetlerinde yaşanacak düşüş de firmanın ekonomik performansının iyileşmesine katkı sağlayabilmektedir. Uzzi (1996) de çalışmasında bu tarz avantaja sahip firmaların hayatta kalma olasılıklarının diğerlerine göre daha fazla olduğunu ortaya koymaktadir ${ }^{3}$.

Her ne kadar zayıf bağların, aktörün etrafındaki kümeden elde edemeyeceği ve bu kümenin ötesinde var olan bilgiye ve kaynaklara ulaşmasına yardımcı olsa da güçlü bağların hem ihtiyaç duyulan bilgiye ve kaynaklara daha kolay erişim sağlamakta hem de yardımcı olmak konusunda daha istekli olmaktadır (Granovetter, 1983: 209).

Yazında güçlü bağların sağladığı bütün bu avantajlar değerlendirildiğinde, aktörü örgüt olan ağlar içerisinde yer alan güçlü bağların sağladığı avantajların, firmaların reel olarak çıktıları üzerinde etki yaratması beklenmektedir. Bu etkinin açığa çıkartılabilmesi adına geliştirilen araştırma modeli Şekil 1'de verilmektedir. Bu model sayesinde, güçlü bağ yapıları aracılığıyla sosyal sermayesini artıran bir firmanın, elde ettiği kaynak ve bilgi faydalarının finansal performans çıktısı üzerinde olumlu bir etki yaratıp yaratmadığını test edebilmek mümkün olmaktadir.

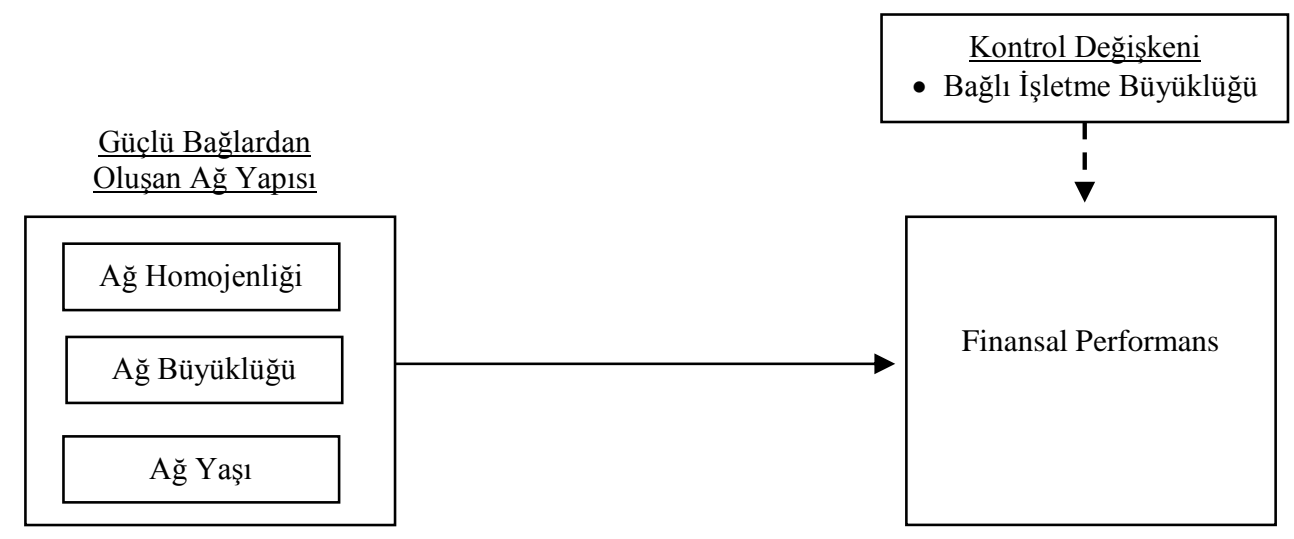

Şekil 1: Güçlü Bağlardan Oluşan Ă̆ Yapısı ile Finansal Performans Arasındaki İlişkiyi Açıklayan Araştırma Modeli

\footnotetext{
${ }^{3} \mathrm{Bu}$ noktada bir de gruplar arasında oluşan boşluklardaki aracılık firsatlarını değerlendiren aktörlerin daha avantajlı olduğunu söyleyen Burt (2000a, 2000b)'e ait yapısal boşluklar yaklaşımından söz edilebilir. Fakat çalışmanın amacı doğrultusunda gruplar arasındaki değil grup içerisindeki aktörler arasında kurulan bağların etkisi araştırıldığından bu yaklaşıma değinilmeyecektir.
} 


\subsection{Literatür Taraması ve Geliştirilen Hipotezler}

Güçlü bağ-zayıf bağ tartışması konusunda, farklı düzeydeki aktörlerin bağ yapılarının incelendiği ve farklı sonuçlara ulaşıldığı birçok çalışmadan oluşan zengin bir yazın araştırmacılara yol göstermektedir (Granovetter, 1973; Lin ve diğerleri, 1981; Obukhova, 2012; Battilana ve Casciaro, 2013; Perry-Smith, 2014). Örgüt temelli yapılan çalışmalarda ise performans ve yenilikçilik üzerinde bir yoğunlaşma olduğu göze çarpmaktadır (Sparrowe ve diğerleri, 2001; Tsai, 2001). Hem yaratıcılığın teşvik edilerek yeniliklerin ortaya çıkartılabilmesi için bilgiye erişim ve bilgi paylaşımının önemi, hem de örgüt performansını iyileştirecek tecrübe ve kaynaklara erişimin işletmeyi finansal ve stratejik açıdan son derece rahatlatabilecek olması firmalar için bilgi ve tecrübenin değerini ortaya koymaktadır. $\mathrm{Bu}$ anlamda bilgiye zamanında ve hızla değișen piyasalarda herkesten önce erişim de büyük bir avantajın elde edilmesine olanak tanıyacaktır.

Burada asıl cevaplandırması gereken soru, yazındaki tartışmadan da yola çıkarak ne tür bir bağın bu avantajı yaratabilecek olduğudur. Bu konuda da yazında tam bir uzlaşıdan söz edilememektedir. Batjargal (2003) zayıf bağların firma performansına olumlu etkisi olduğunu ortaya koyarken Lowik ve diğerleri (2012) hem zayıf bağların hem de güçlü bağların firmalar tarafından bilgi edinmek için kullanıldığını fakat güçlü bağların özellikle sürdürülebilir bilgi akışı için bir kaynak olduğunu göstermişlerdir. Uzzi ve Lancaster (2003)'da yine herkes tarafından erişilemeyen özel bilgilerin, birbirine güçlü ilişkilerle bağlı olan firmalar arasında aktarımının mümkün olduğunu, bunun tersine kol-mesafesindeki örgütlerle olan ilişkilerdeki örtük bilgi aktarımının negatif olduğunu belirtmektedir. Daha çabuk ve daha kapsamlı bir şekilde bilgiye erişim imkânı olan aktörlerin daha avantajlı konumda bulunmaktadırlar (Burt, 2000a: 351). Özellikle de rekabetin gün geçtikçe arttığı gerçeğini göz önünde bulundurursak sürekli bilgi akışının sağlanması çok daha stratejik hale gelmekte ve bu konuda firmaya destek olabilecek her türlü işlem önemli olmaktadır.

Güçlü bağlar ve zayıf bağlara dair çelişkili sonuçlar üreten yazının varlığı, farklı bağlamların farklı sonuçlar üretebileceğini (Alguezaui ve Filieri, 2010; Malik, 2012) ve araştırmacıların doğru cevabı bulabilmeleri için bağlamın kendine özgü niteliklerine bakmaları gerektiği gerçeğini ortaya koymaktadır. Fakat özellikle son yıllarda, farklı avantajlara sahip olan farklı bağ yapılarının her ikisinin de firmaya önemli getirileri olduğu için aslında iki tür ilişkinin birbirinin eksiklerini tamamlayarak işletmeyi, tek başına güçlü ya da zayıf bağların sağlayamayacağı bir noktaya ulaştıracağ 1 sonucuna ulaşan araştırmalara da rastlanmaktadır (Tiwana, 2008; Tomlinson, 2011; Michelfelder ve Kratzer, 2013). Bu çalışmalar içerisinde özellikle Rost (2011) tarafından yürütülen araştırma neticesinde ulaşılan sonuç dikkat çekicidir. Yazar, sözü edilen çalışmasında güçlü bağların varlığında, yapısal boşluklar veya merkeze uzak ağ pozisyonları gibi zayıf ă̆ yapılarının, güçlü bağların gücünü daha da artırdığını ortaya koyarak zayıf ağ yapılarının, güçlü bağlar olmadan herhangi bir anlam ifade etmediğini fakat güçlü bağların 
zayıf ağ yapıları olmasa da değerli olduğunu, sadece bu değerin zayıf ağ yapıları sayesinde artırıldığını ifade etmektedir (Rost, 2011: 589).

Türkiye bağlamında örgütlere fayda yaratacak bağ yapısının güçlü bağlar mı yoksa zayıf bağlar mı olacağı sorusunun ise yukarıda vurgulandığı gibi, bağlamın etkisi dikkate alınarak cevaplandırılması gerekmektedir. Bu noktada Kozan ve Akdeniz (2014) tarafından gerçekleştirilen ve büyüklüğün hem ürün gamının genişletilmesi hem de bilgi ediniminin artırılması olarak iki farklı açıdan ele alındığ1 çalışmada, Türkiye bağlamında küçük işletmelerin kurduğu güçlü bağların, işletmelerin büyümeleri üzerinde pozitif etkisi olduğu, buna karşın zayıf bağların her iki büyüme kıstası üzerinde de etkisi olmadığı sonucu ortaya koyulmaktadır. Yazarlar bunun sebebinin hem finansal yardım alma hem de bilgisine başvurma konusunda işletme sahiplerinin grup dışındansa ait oldukları gruba daha çok güveniyor olmalarına sebep olan hâkim kollektivist kültürel yapının varlığı olabileceğini belirtmektedirler.

Sosyoloji ve sosyal psikoloji alanlarında gerçekleştirilen araştırmaların genel bulgularından bir tanesi bilginin, gruplar arasında değil grup içerisinde (departmanlar arasından ziyade departman içerisinde, endüstriler arasından ziyade endüstri içerisinde-ya da işletme grupları arasında değil işletme grubu içerisinde) daha çok dolaştığıdır (Burt, 2000a: 350-352, 2000b: 4). Bu sebeple bireylerin mevcut firsatlardan eş zamanlı olarak haberleri olamamakta, her ne kadar bilgi sonunda herkese yayılsa da bu yayılım zaman almakta ve bu nedenle bilgiye erken ulaşan bireyler daha avantajlı olmaktadır (Burt, 2000a: 351). Hem bu nedenle hem de Kozan ve Akdeniz (2014)'in de çalışmalarında değindikleri hâkim kültürel anlayış nedeni ile Türkiye bağlamında, kurulan güçlü bağlar sayesinde bilgi aktarımın zayıf bağlara oranla daha etkin gerçekleşmesi ve güvenin oluştuğu sosyal bir yapı sayesinde hem daha detaylı ve daha özel bilgilerin paylaşılması hem de paylaşılan bu bilgilerin daha çok dikkate alınması beklenmektedir. $\mathrm{Bu}$ sebeple aşağıda yer verilen hipotez geliştirilebilmektedir:

$H_{1}$ : Işsletmenin güçlü băgları finansal performans üzerinde pozitif yönde etkili olacaktır.

$\mathrm{Bu}$ çalışma kapsamında ise Kraatz (1998) tarafından gerçekleştirilen çalışma esas alınarak güçlü bağların kurulduğu ağ yapısının özellikleri üzerinden hareket edilmekte ve bu yapı üç farklı özellik ile bağdaştırılabilmektedir. Bunlardan ilki Granovetter (1973) ve Krackhardt (1992) tarafından da ortaya koyulan ve bağın gücünün bir belirleyicisi olan zaman faktörüdür. Bir diğeri ise taraflar arasındaki etkileşimin sıklığını belirleyecek olan ağ büyüklüğüdür. Küçük ağlarda geniş ağlara göre aktörlerin birbirleriyle daha sık etkileşim içerisinde olma dereceleri artabilmektedir (Kraatz, 1998: 624). Son olarak da birbirine benzer aktörler arasında etkileşimin, iletişimin ve samimiyetin artacağına olan inançtır. Ayrıca Karaevli (2008) ve Özkara ve diğerleri (2008)'nin de araştırmalarında belirttikleri üzere Türk işletme gruplarının son yıllarda daha odaklı bir çeşitlenme faaliyetleri göstererek eskisine göre daha az sektörde, daha az iş birimi ile fakat ürün 
çeşitliliğinde artış şeklinde gösterdikleri eğilim de işletme grupları içerisinde oluşan ağın giderek küçüldüğünün ve homojenleştiğinin bir göstergesi olabilmektedir. Bütün bu bilgiler ve çalışmalar 1şığında güçlü bağlardan oluşan ağ yapısının test edilebilmesi adına yukarıda yer verilen hipotez aşağıdaki şekilde alt hipotezlere ayrılmaktadır:

$H_{1 a}$ : Işsletmenin içinde yer aldiğg ăg küçüldükçe, işletmenin finansal performansı artacaktır.

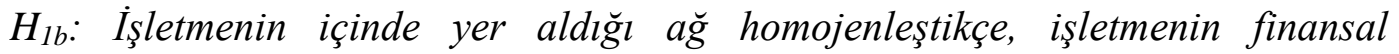
performansi artacaktır.

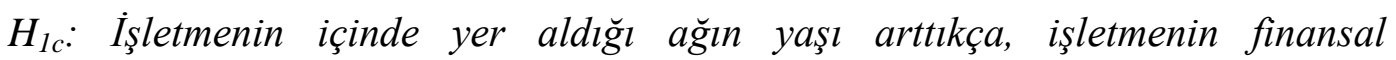
performansi artacaktır.

\section{Metodoloji}

\subsection{Araştırma Bağlamı}

Türkiye'de "holding" ismi ile anılan işletme grupları "ortak girişimcilik ve finansal kontrol altında farklı piyasalarda faaliyet gösteren ve benzer kişisel veya etnik ortak geçmişe dayanan kişilerarası güven ilişkileri ile birbirine bağlanmış şirketler topluluğu" (Leff, 1978: 663) şeklinde tanımlanmakta olup genellikle geç gelişen ekonomilerde ortaya çıkan bir formdur (Ataay, 2012: 74). Bu form pazar eksikliklerine bir cevap olarak ortaya çıkmakta (Leff, 1978: 666) ve ihtiyaç halinde bağlı işletmeleri arasında aracılık yaparak bu eksikleri giderebilmektedir (Özgen ve Özgen, 2009: 327).

Türkiye bağlamında her ne kadar vergi avantajlarından yararlanmak ve transfer fiyatlaması uygulamalarını gerçekleştirmek için bir holding yapısı oluşturulsa da (Buğra, 2010: 259-260) devletin sebep olduğu politik belirsizlik nedeni ile kurucu aileler şirket faaliyetleri üzerinde daha fazla kontrole sahip olmak istemektedirler (Buğra, 2010: 263-265). Bu durumun da etkisi ile işletme gruplarının yapısı daha çok ana şirketin "beyin", bağlı şirketlerin ise "uzuvlar" olarak çalıştığı ve ana şirket yönetim kurulunun kurucu aile üyelerinden oluştuğu bir yap1 olarak karşımıza çıkmaktadır (Buğra, 2010: 285). Oluşturulan bu yapı aracılığı ile işletme gruplarına bağlı firmalar arasında hem her türlü kaynaklarının değişsimini gerçekleştirerek işlem maliyetlerini düşürebilme hem de bilginin değişimini sağlayarak koordineli bir şekilde çalışabilme ve daha maliyetli veya ulaşılması başka türlü mümkün olmayan bilgiye ulaşabilme imkânı oluşmaktadır (Şahin ve Mert, 2014: 79). Yaratılan böyle bir iç piyasa, grup şirketleri arasında işbirliğinin sağlanması ve hem bağlı işletme bazında hem de grup bazında performansın ve stratejilerin bu durumdan etkilenmesi mümkün olabilmektedir.

\section{2. Örneklem}

Çalışmanın analizleri örgüt düzeyinde yürütülmüştür. İşletme gruplarının kendi içlerinde bir a ̆g yapısı oluşturmaları ve bu ağ sayesinde bilgi, kaynak değişimi ve sosyal sermaye paylaşımı gerçekleştirebiliyor olmaları, işletme grupları içerisinde 
oluşturulan a $\breve{g}$ yapısından hareketle hipotezlerin test edilebilmesine olanak sağlamaktadır. $\mathrm{Bu}$ noktadan hareketle ve araştırmanın amacı ve kısıtları doğrultusunda ana evren Borsa İstanbul'da (BIST) işlem gören ve bir işletme grubuna bağlı faaliyet gösteren bütün işletmeleri kapsamaktadır. BIST'deki işletmeler incelendiğinde 16.03.2014 tarihi itibari ile herhangi bir pazarda, en az bir tane işlem gören şirketi olan toplam 121 adet işletme grubu olduğu görülmektedir. Bu işletme gruplarına bağlı ve yine BIST'de herhangi bir pazarda işlem gören firma sayısı ise 1 ile 19 arasında değişmektedir. Bazı firmaların sadece ana firması olan holding şirketi halka açıkken, bazı grupların sadece bağlı şirketleri, bazılarının ise hem ana şirketi hem de bağlı şirketleri halka açıktır (http://www.kap.gov.tr/sirketler/islem-goren-sirketler/tum-sirketler.aspx.

Çalışmanın ana evreni, hipotezlerin analiz edilebilmesi için aşağıdaki kıstasları taşıyan firmalardan oluşacak şekilde daraltılmıştır:

1. Menkul kıymet yatırım ortaklıkları, gayrimenkul yatırım ortaklıkları, girişim sermayesi şirketleri, sigorta şirketleri, finansal kiralama ve faktöring şirketleri ve bankalar gibi finansal kuruluşlar, bilanço ve gelir tablosu yapıları farklı olduğu için örneklem dışında bırakılmıştır. Bu şirketlere karar verebilmek için sadece BIST Mali Pazarda kayıtlı bir firma olması yeterli bir kıstas olarak görülmemiş, sadece portföy yatırımları yapmak, menkul kıymet almak-satmak vb. için kurulmuş firmalar örneklem dışında bırakılırken; yine BIST Mali Pazarda kayıtlı olmasına rağmen bu faaliyetlerin dışında da faaliyetleri bulunan firmaların şirket/grup amaçları okunarak, bu firmaların da örnekleme dahil edilmelerine karar verilmiştir.

2. Piramit yapının tepesinde bulunan işletme grubunun merkez firmaları, bağlı şirketleri bir çatı altında topladığ 1 için örneklemden çıkartılmıştır.

3. Örneklem içerisine dâhil edilecek firmaların 2010-2013 yılları arasındaki performans verilerinin kullanılacak olması nedeni ile bu tarihten sonra kurulan ve bu nedenle herhangi bir yıla ait finansal verilerine ulaşılamayan firmalar örneklem dişı bırakılmıştır. Ayrıca örnekleme dâhil edilecek bütün firmaların bu yıllar arasında hep aynı gruba bağlı olarak çalışmış olmaları, herhangi bir şekilde el değiştirmiş olmamaları ve şirket yapısını değiştirerek 1 numaralı maddede bahsedilen türde bir şirket olarak faaliyetlerine devam etmemiş olmaları da bir kıstas olarak belirlenmiştir. Bunun sebebi, şirket türü değiştiği takdirde, mali tablo yapısının da değişikliğe uğramasıdır. Bir şirkete aynı anda ortak olan iki veya daha fazla işletme grubu var ise, sözü edilen şirket, hisse oranı daha fazla olan işletme grubuna dâhil edilmiştir. En büyük hissedar olmamakla birlikte, örneklem içerisinde yer alan işletme gruplarından herhangi birisinin sahibinin, yönetim kurulunda yer alarak bağımsız olmayan üye vasfi ile görev yaptığı işletmeler de yönetim kurulunda yer alan üyenin sahibi olduğu işletme grubuna ait olarak değerlendirilmiştir. 
4. Göz önüne alınan bütün bu kıstasların yanı sıra, son bir kıstas olarak araştırmanın temel hipotezlerinden olan merkeziyet derecelerinin ölçülebilmesi için bir grup içerisinde en az 3 tane firmanın bulunuyor olması gerekmektedir. Bu sebeple bağlı işletme sayısı 3'den az olan gruplar ve bağlı işletmeleri de örneklemden çıkartılmıştır.

$\mathrm{Bu}$ kısıtlar çerçevesinde, örneklem 15 işletme grubuna ait toplamda 74 adet bağlı kuruluştan oluşmaktadır. Bu işletmelerin sektörlere göre dağılımı Tablo 1'de özetlenmektedir. Tablo 1'e göre örneklem içerisinde yer alan bağlı işletmelerin çok büyük bir kısmı $(\% 70,3)$ imalat sektöründe faaliyet gösteren işletmelerden oluşmaktadır.

Tablo 1: Örnekleme Dâhil Edilen İşletmelerin Sektörlere Göre Frekans Dağılımları ${ }^{4}$

\begin{tabular}{lcc}
\hline Sektör & Frekans & Yüzde (\%) \\
\hline İmalat & 52 & 70,3 \\
Holdingler ve Yatırım Şirketleri & 8 & 10,8 \\
Toptan ve Perakende Ticaret, Otel ve Lokantalar & 6 & 8,1 \\
Maden & 4 & 5,4 \\
Teknoloji & 3 & 4 \\
Elektrik, Gaz ve Su & 1 & 1,4 \\
\hline Toplam & $\mathbf{7 4}$ & $\mathbf{1 0 0}$ \\
\hline
\end{tabular}

\subsection{Değişkenler ve Ölçümleme}

Bağımlı Değişken: Araştırmanın bağımlı değişkeni, bağlı işletmenin finansal performansıdır. Finansal performansı ölçmek için yazında kullanılan farklı değişkenler mevcuttur fakat bunların en uygununun hangisi olduğuna dair bir uzlaşı gerçekleşmemektedir (Elsayed, 2011: 426). Bununla birlikte sosyal sermayenin performans üzerindeki etkisini araştıran çalışmalarda (Karahanna ve Preston, 2013; Lee ve diğerleri, 2012; Li ve diğerleri, 2011; Andersen ve Olsen, 2011) sıklıkla kullanılan finansal performans ölçülerinin ROA (Return on AssetsAktif Kârlılığg1), ROE (Return on Equity-Özsermaye Kârlılığı) ve ROS (Return on Sales-Satış Kârlılı̆̆g1) olduğu görülmektedir. Hitt ve diğerleri (1997) çalışmalarında ROE'nin işletmenin sermaye yapısına çok duyarlı olduğunu, ROA ile ROS'un ise zaten yüksek korelasyona sahip olan değişkenler oldukları için benzer sonuçlar üreteceklerini öne sürerek bağımlı değişken olarak sadece ROA'yı kullanmışlardır. Bu tespit nedeni ile bu çalışma kapsamında da finansal performans ölçütü olarak ROA kullanılmaktadır.

Finansal performans ölçütleri (örneğin ROA) bazı çalışmalarda iki yıl ortalaması alınarak kullanılabilmektedir (Goll ve Rasheed, 2004). Böyle bir yol izlenerek firma performansı üzerinde oluşabilecek geçici etkiler dikkate alınmış

\footnotetext{
4 Kamuyu Aydınlatma Platformu'nda yer alan sektör sınıflaması referans alınmıştır (http://www.kap.gov.tr/sirketler/islem-goren-sirketler/sektorler.aspx, Erişim: 16.03.2014).
} 
olabilecektir (Sambharya, 1995: 208). Çalışmanın amacı açısından değerlendirildiğinde ise işletmeler arası kurulan bağlar aracılığ ile paylaşılan bilgi ve kaynakların finansal performans üzerindeki etkilerinin gecikmeli olarak ortaya çıkabileceği düşünülmektedir. Bu nedenle bağımlı değişken olarak ele alınan finansal performans ölçülerinin çalışmanın baz yılı olan 2010 ve izleyen yıllar olan 2011, 2012 ve 2013 için ayrı ayrı hesaplanarak bu değerlerin ortalaması analizlere dahil edilmiştir. Finansal performans ölçütünün hesaplanmasında kullanılan net kâr ve toplam aktifler değerlerine ilişkin veriler, firmaların Kamuyu Aydınlatma Platformu'nda (KAP) yayınladıkları sözü edilen yıllara ait bağımsız denetimden geçmiş finansal tablolarından elde edilmişstir.

Bağımsız Değişken: Güçlü bağlardan oluşan ağ yapısının ölçülebilmesi için yazındaki öncül çalışmalar referans alınarak (Kraatz, 1998) bir bağlı işletmenin yer aldığı ağın büyüklüğü, homojenliği ve ağın yaşı değişkenleri kullanılmaktadır. Bu değişkenlerin ölçülmesinde 2010 yılındaki ağ yapıları temel alınmaktadır. A $\breve{g}$ büyüklüğü, işletme grubunun örneklem içerisinde yer alan bağlı işletme sayısı ile ölçülmektedir. Ağın yaşı ise işletme grubunun örneklem içerisine dâhil edilen işletmelerinden en eski olanın kuruluş tarihi ile temel alınan 2010 yılı arasındaki farktan oluşmaktadır.

Bir diğer değişken olan homojenlik ise ürün çeşitlenmesi hesaplaması kullanılarak yapılmıştır. Örneklem içerisinde yer alan bağlı işletmelerin ne kadar homojen bir yapılanma gösterdiklerini belirleyebilmek için yazında pek çok çalışmada da kullanılan (Ahuja, 2000; Hitt ve diğerleri, 1997; David ve diğerleri, 2010; Mahmood ve diğerleri, 2011) aşağıda yer alan formülden yararlanılmaktadır (Palepu, 1985: 252-253):

$$
D T=\sum_{i=1}^{N} P_{i} \ln \left(\frac{1}{P_{i}}\right)
$$

(1) numaralı formüldeki DT, toplam çeşitlenme düzeyini, Pi ise i sektör satışlarının toplam satışlar içerisindeki payını ifade etmektedir. Söz konusu ölçüm kullanılırken ilişkili veya ilişkisiz ürün gruplarına karar verilebilmesi gerekmektedir. Bunun için ise Amerikan ekonomisi içerisinde ekonomik faaliyetlerin sinıflandırılması amacı ile kullanılan (Montgomery, 1982: 299) Standart Sektör Sinıflandırması (SIC) kodları esas alınmıştır (http://www.osha.gov/pls/imis/sicsearch.html, Erişim: 17.07.2014). Her grup için, grup içerisindeki bağlı işletmelerin yer aldıkları sektör kodları oluşturulmuştur. Dört basamaklı kodlardan oluşan bu sınıflandırma sistemi içerisinde ilk iki basamak numarası aynı olan sektörler ilişkili kabul edilmektedir (Hitt ve diğerleri, 1997: 779). Homojenlik düzeyini ölçebilmek için, işletme grubuna bağlı şirketlerin her birinin finansal tablo dipnotlarında belirtilen satış gelirleri ve bu gelirlerin elde edildikleri sektörlerden faydalanılmıștır. Bağlı işletmenin bulundukları grubun homojenlik düzeyini ifade edebilmek için tek bir indeks değeri hesaplanmıştır. 
Kontrol Değişkeni: Çalışmada, bağlı işletme düzeyinde işletme büyüklüğü kontrol değişkeni olarak ele alınmıştır. Bağlı kuruluş büyüklüğü, ölçek ekonomilerinden faydalanarak maliyetlerin düşürülmesine (Mahmood ve diğerleri, 2011: 831) yardımcı olabilecektir. Bu etki ise firmanın kârlılık düzeylerinin artmasına sebep olacağı için, bağlı işletmelerin finansal performansları arasında gerçekçi bir kıyaslama yapılabilmesi adına işletme büyüklünün kontrol edilmesi gerekmektedir. Öncül çalışmalara bakıldığında işletme büyüklüğünün ölçülebilmesi için çalışan sayısı (Contractor ve diğerleri, 2003), toplam satışlar (Hitt ve diğerleri, 1997) ve toplam aktifler (Goll ve diğerleri, 2001) gibi farklı değişkenlerin kullanıldığ 1 göze çarpmaktadır. Bu çalışma için ise toplam satışlar işletme büyüklügünün ölçülmesinde dikkate alınmıştır. Bu değerler ise firmaların KAP'da yer alan mali tablolarından elde edilmiştir.

\subsection{Analiz ve Bulgular}

Çalışmada kullanılan veri setine $(n=74)$ dair tanımlayıcı istatistikler ve değişkenler arasındaki Pearson korelasyon katsayıları Tablo 2'de özetlenmektedir. Katsayılar incelendiğinde, finansal performans ile bağımsız değişkenlerin hiçbiri arasında istatistiksel olarak anlamlı bir ilişkiye rastlanamamaktadır $(\mathrm{P}>, 05)$. Kontrol değişkeninin ilişki katsayılarına bakıldığında ise sadece ağ homojenliği $(\mathrm{r}=0,243)$ ve ă̆ büyüklüğ̈̈ ile $(\mathrm{r}=0,268)$ istatistiksel olarak anlamlı $(\mathrm{P}<, 05)$ ilişkilere rastlanmaktadır. Korelasyon matrisi, bağımsız değişkenler arasındaki ilişki katsayılarının ,80’den düşük olduğunu göstermektedir. Bu durum, çoklu doğrusal bağlantı (multicollinearity) sorununun ortaya çıkmadığını göstermektedir (Bryman ve Cramer, 1997: 257).

Tablo 2: Değişkenlerin Tanımlayıcı İstatistikleri ve Değişkenler Arasındaki Pearson Korelasyon Katsay1ları

\begin{tabular}{|lcccccc|}
\hline Değişkenler & $\overline{\boldsymbol{X}}$ & $\mathbf{\text { s.d. }}$ & $\mathbf{1}$ & $\mathbf{2}$ & $\mathbf{3}$ & $\mathbf{4}$ \\
\hline 1-ROA (2010-2013) & 0,0503 & 0,0948 & 1 & & & \\
2-AĞHOM & 0,9623 & 0,4740 & $-0,001$ & 1 & & \\
3-AĞBÜY & 5,8108 & 2,2001 & 0,016 & $0,363^{* *}$ & 1 & \\
4-AĞYAŞ & 46,8243 & 14,3406 & $-0,055$ & $0,408^{* *}$ & 0,182 & 1 \\
5-BÜYÜKLÜK & 1493702922,12 & 3413666096,91 & 0,069 & $0,243^{*}$ & $0,268^{*}$ & 0,108 \\
\hline "P<,05; "P< $\mathrm{P}<, 01$ & & & & & &
\end{tabular}

Not: ROA (2010-2013): 2010-2011-2012 ve 2013 yılları finansal performans ortalamasını, AĞHOM: Bağlı işletmenin bulunduğu ağın homojenlik düzeyini, AĞBÜY: Bağlı işletmenin bulunduğu ağın büyüklüğünü, AĞYAŞ: Bağlı işletmenin bulunduğu ağın yaşını ve BÜYÜKLÜK: Satış gelirleri cinsinden ölçülen büyüklük değerini ifade etmektedir.

Tablo 3 araştırma hipotezlerinin test edilmesi için gerçekleştirilen regresyon analizlerinin sonuçlarını göstermektedir. Gerek kontrol değişkeninin dâhil edilmediği ilk model $(\mathrm{F}=0,092 ; \mathrm{P}>, 10)$, gerekse kontrol değişkeninin dâhil edilerek analizlerin yapıldığ ikinci modelin $(\mathrm{F}=0,151 ; \mathrm{P}>, 10)$ istatistiksel olarak anlamlı olmadıkları görülmektedir $(\mathrm{P}>, 05)$. Elde edilen bu analiz sonuçları "işletmenin içinde yer aldiğl ăg küçüldükçe, işletmenin finansal performansı artacaktır" şseklinde ifade edilen $\mathrm{H}_{1 \mathrm{a}}$, "işletmenin içinde yer aldiğ a ă 
homojenleştikçe, işletmenin finansal performansı artacaktır" şeklindeki $\mathrm{H}_{1 \mathrm{~b}}$ ve yine "işletmenin içinde yer aldı̆̆ performansı artacaktır" şeklinde ifade edilen $\mathrm{H}_{1 \mathrm{c}}$ hipotezlerimizin tamamının reddedildiği anlamına gelmektedir.

Tablo 3: Regresyon Analiz Sonuçları*

\begin{tabular}{|lccc|ccc|}
\hline \multirow{2}{*}{\begin{tabular}{c} 
Değişkenler \\
\cline { 2 - 7 } Bağımsız Değişkenler
\end{tabular}} & $\boldsymbol{\beta}$ & $\mathbf{t}$ & $\mathbf{P}$ & $\boldsymbol{\beta}$ & $\mathbf{t}$ & $\mathbf{P}$ \\
\hline AĞGOM & 0,018 & 0,129 & 0,898 & 0,006 & 0,041 & 0,968 \\
AĞBÜY & 0,022 & 0,168 & 0,867 & 0,006 & 0,049 & 0,961 \\
AĞYASŞ & $-0,066$ & $-0,503$ & 0,617 & $-0,066$ & $-0,502$ & 0,617 \\
Kontrol Değişkeni & & & & & & \\
BÜYÜKLÜK & & & & 0,073 & 0,575 & 0,567 \\
\hline Adjusted R R & $-0,039$ & & $-0,049$ \\
F-Model Değeri & 0,092 & 0,964 & \multicolumn{2}{|c|}{0,151} & 0,962 \\
\hline
\end{tabular}

*Finansal performans (ROA (2010-2013)) bağımlı değişkendir

\subsection{Tartışma}

$\mathrm{Bu}$ araştırma, yazında yer alan güçlü bağ-zayıf bağ tartışmasına, gelişmekte olan bir ülke bağlamında ve bu bağlamın ekonomik aktörünü konu edinerek 1şık tutmaya çalışmaktadır. Yazındaki güçlü bağ-zayıf bağ tartışması, bağlamın kendine özgü özellikleri göz önünde bulundurularak üzerinde çalışılması gerekli bir konudur. $\mathrm{Bu}$ noktaya dikkat edilerek çalışma kapsamında gerçekleşmesi beklenilen ilişkiler üzerinde durulmuştur.

Çalışma kapsamında güçlü băg yapılarından oluşan bir ağın sahip olduğu özelliklerden hareketle, örgütlerin sahip oldukları güçlü bağların, finansal performansları üzerindeki etkileri ele alınmış ve modele dâhil edilen hiçbir özellik açısından istatistiksel olarak anlamlı sonuçlar elde edilememiştir. Bu durum yazında yer alan iki karşıı görüşten bir tanesinin Türkiye bağlamında destek bulmadı̆̆

Aynı düzeyde erişilebilir yerleşik kaynaklar mevcutken bazı bireylerin, diğerlerine göre, kaynakları daha iyi harekete geçirebilmelerinin nedeni olarak aktörün bulunduğu ağ içerisindeki konumu gösterilmektedir (Lin, 1999: 42). Fakat bu konumun Burt (2000a; 2000b) tarafından ileri sürülen yapısal boşluklar açısından zengin bir konum olması gerekmektedir (Lin, 1999: 42). Bu noktada asıl fark1 yaratan köprü görevi görmek veya köprü görevi gören bir aktöre yakın olabilmektir (Lin, 1999: 42).

Benzer bir şekilde James Coleman (1988a, 1988b) tarafından öne sürülen sosyal kapalılık yaklaşımı da yapısal boşluklar ile birleştikleri zaman gerçek anlamını bulmaktadır (Burt, 2000a: 397). Kendi içerisinde kapalı bir grup, grup dişındaki yapısal boşlukları fark ederek bu boşlukları doldurabildiği zaman çok daha yüksek 
performanslar gösterebilmektedir (Burt, 2000a: 397). Bu noktada elbette ki örneklem içerisinde yer alan firmaların doldurdukları yapısal boşluklar olup olmadığı ya da böyle bir aracılık ilişkisine sahip olup olmadıkları bu araştırma kapsamında konu edilmemiştir. Fakat elde edilen bulgular, ayrıca Türk işletme grupları kendi içlerinde çok kapalı ve diğerlerinden izole bir şekilde mi faaliyet göstermektedirler sorusunu akla getirmektedir. Bir ülkenin ekonomisi açısından değerlendirildiğinde bile güven temelli güçlü bağların egemen olduğu bağlamlarda daha kapalı ve denetime dayalı bir ekonomiden, zayıf bağlarla kurulan ilişkilerin yoğun olduğu bağlamlarda ise bilgiye ve değişime daha açık bir anlayıştan bahsetmek mümkünken (Sözen, 2007: 24), aynı etkilerin işletme gruplarında ya da sektörlerde ortaya çıkması da beklenebilmektedir. Canbolat (2011), yapısal boşluklar yaklaşımı üzerinden sosyal sermayeyi ölçtüğü ve Türkiye bağlamındaki işletme gruplarını ele aldığı çalışmasında, sosyal sermayesi fazla olan işletme gruplarının çeşitlendiklerini fakat bu stratejinin daha çok ilişkisiz çeşitlenme şeklinde gerçekleştiği sonucunu ortaya koymuştur. Aslında bu çalışma da Türk işletme gruplarına atfedilen karakteristik bir özelliğin temelinde yapısal boşluklar yaklaşımının yattığına bir işaret sayılabilir.

Ayrıca, yerleşik kaynakların sağlayabileceği avantajların bilişsel olarak farkına varılması da önemlidir (Lin, 1999: 42). Bu durumda yapısal boşlukların olmaması kadar bu durumun farkına varılamamış olması da güçlü bağlardan oluşan bir ağ yapısının, firmanın çıktıları üzerinde beklenilen etkiyi yaratamamış olması da mümkündür.

\section{Sonuç}

Aktörün sahip olduğu bağların yapısının, aktöre olan etkilerinin araştırıldığı ve aktörün bir işletme grubuna bağli firmalardan seçildiği bu araştırma kapsamında, üzerinde çalışılan bağlamı daha iyi ifade ettiği düşünülen güçlü bağ yapılarına dair hipotezler test edilmiştir. Fakat güçlü bağlardan oluşan ağ yapılarının finansal performans üzerinde anlamlı etkiler oluşturmaması, özellikle örtük bilgi paylaşımını kolaylaştırdığı düşünülen bu tür bir yapının Türkiye bağlamında geçerli olmayabileceği sonucunu ortaya koymaktadır. $\mathrm{Bu}$ noktada elbette firmaların bilgiyi paylaşabilme ya da ilişki içerisinde oldukları diğer firmalardan bilgi edinebilme ve bu bilgiyi kullanabilme yetenekleri sorgulanmamakla birlikte bilgi edinimini gerçekleştirebilmenin, bu bilgiyi avantaj yaratacak şekilde kullanmanın ön koşulu olduğunu unutmamak gerekmektedir.

Yapılan araştırmanın kendi içerisinde kısıtları bulunmaktadır ve bu kısıtlar elde edilen sonuçlar değerlendirilirken göz önünde bulundurulmalıdır. $\mathrm{Bu}$ anlamda çalışmanın en temel kısıtı verilerin ulaşılabilirliği nedeniyle sadece BIST'de işlem gören firma örnekleminde çalışılmış olunmasıdır. Aynı kısıt performans verilerinin elde edilmesi noktasında da karşımıza çıkmış ve bu kısıt, sadece mali tablolardan elde edilebilecek performans verileri üzerinden hareket edilmesine yol açmıştır. 
Bu kısıtın yanı sıra güçlü bağların test edilmesinde ilişkiler, ağ yapısı üzerinden gidilerek test edilmiştir. Fakat Granovetter'in (1973) çalışmasında vurguladığı ve bir bağın gücünü belirleyen etkenler üzerinden bağların gücü hesap edilerek bu kısıt da aşılabilecektir. Ayrıca, firmalar sadece grup içerisinde yer alan diğer bağlı şirketlerle değil, birçok farklı üçüncü tarafla da ilişki içerisinde bulunup bağ kurabilmektedirler. Hâlbuki çalışma kapsamında sadece grup içerisindeki bağlar dikkate alınmıştır. $\mathrm{Bu}$ durum, elde edilen sonuçların genelleştirilebilmesi anlamında kısıtlar ortaya çıkarmaktadır. Ayrıca çalışma kapsamında firmaların yer aldıkları ağlar içerisinde bilgiyi paylaşmalarına vurgu yapılmakla birlikte, firmaların bilgiyi paylaşabilme veya edindikleri bilgiyi içselleştirebilme yetenekleri göz ardı edilmektedir. Bu sebeple bilgiyi, faaliyetleri şekillendirmekte kullanılabilecek hale dönüştürme yeteneğine sahip firmalar üzerinde gerçekleştirilecek bir çalışma farklı sonuçların ortaya çıkmasına da katkı sağlayabilecektir.

Sözü edilen bu kısıtları aşabilmek adına gelecek çalışmalarda başvurulabilecek bir yol, nitel yöntemler kullanılarak firmalar arasında var olan bağların gücünün ölçülmesine yönelik olabilecektir. Ayrıca güçlü bağlara dair incelemelerin yanı sıra yazında da vurgulandığı gibi hem güçlü bağları hem de zayıf bağları veya yapısal boşluklardaki aracılık faaliyetlerini üstlenen firmalar için durumun ne yönde şekilleneceği araştırma konusu yapılabilecektir. Bunun da ötesinde örneğin bağlantıları açısından birbirine benzeyen firmaların performansları açısından da benzeşip benzeşmedikleri veya benzeşmiyorlarsa bunun sebepleri çalışma konusu yapılabilecektir.

\section{Kaynakça}

Ahuja, G. (2000), "The Duality of Collaboration: Inducements and Opportunities in the Formation of Interfirm Linkages", Strategic Management Journal, 21(3), 317-343.

Alguezaui, S. ve Filieri, R. (2010), "Investigating the Role of Social Capital in Innovation: Sparse Versus Dense Network", Journal of Knowledge Management, 14(6), 891-909.

Andersen, M. L. ve Olsen, L. (2011), "Corporate Social and Financial Performance: A Canonical Correlation Analysis", Academy of Accounting and Financial Studies Journal, 15(2), 17-38.

Ataay, A. (2012), “Türk Aile İşletme Gruplarının Uluslararasılaşma Deneyimleri”, Tamer Koçel (Ed.), 5. Aile İşletmeleri Kongresi Kongre Kitabı, 7192, İstanbul: İstanbul Kültür Üniversitesi Yayınları.

Baker, W. E. (1990), "Market Networks and Corporate Behavior", American Journal of Sociology, 96(3), 589-625.

Batjargal, B. (2003), "Social Capital and Entrepreneurial Performance in Russia: A Longitudinal Study”, Organization Studies, 24(4), 535-556. 
Battilana, J. ve Casciaro, T. (2013), "Overcoming Resistance to Organizational Change: Strong Ties and Affective Cooptation", Management Science, 59(4), 819-836.

Bourdieu, P. (2002), “The Forms of Capital”, Nicole Woolsey Biggart (Ed.), Economic Sociology içinde (280-291), Oxford: Blackwell Publishers.

Bryman, A. ve Cramer, D. (1997), Quantitative Data Analysis with SPSS for Windows: A Guide for Social Scientists, London and New York: Routledge.

Buğra, Ayşe (2010), Devlet ve İşadamları, 7. Bask1, İstanbul: İletişimYayınları.

Burt, R. S. (1997), "The Contingent Value of Social Capital”, Administrative Science Quarterly, 42(2), 339-365.

Burt, R.S. (2000a), "The Network Structure of Social Capital", Research in Organizational Behavior, 22, 345-423.

Burt, R.S. (2000b), Structural Holes Versus Network Closure as Social Capital, http://snap.stanford.edu/class/cs224w-readings/burt00capital.pdf (Erişim: 20.12.2014).

Canbolat, E. O. (2011), "Social Capital Influences on Business Groups' Diversification Strategies", Procedia-Social and Behavioral Sciences, 24, 14361443.

Coleman, J.S. (1988a), "Social Capital in the Creation of Human Capital", American Journal of Sociology, 94(Supplement), 95-120.

Coleman, J.S. (1988b), "Creation and Destruction of Social Capital: Implications for the Law", Notre Dame Journal of Law Ethics and Public Policy, 3(3), 375-404.

Contractor, F.J. ve diğerleri (2003), “A Three-Stage Theory of International Expansion: The Link Between Multinationality and Performance in the Service Sector ", Journal of International Business Studies, 34(1), 5-18.

David, P. ve diğerleri (2010), "Do Shareholders or Stakeholders Appropriate the Rents from Corporate Diversification? The Influence of Ownership Structure", Academy of Management Journal, 53(3), 636-654.

Elsayed, K. (2011), "Board Size and Corporate Performance: the Missing Role of Board Leadership Structure", Journal of Management and Governance, 15(3), 415-446.

Goll, I. ve diğerleri (2001), “Top Management Team Composition, Corporate Ideology, and Firm Performance”, Management International Review, 41(2), 109129. 
Goll, I. ve Rasheed, A.A. (2004), "The Moderating Effect of Environmental Munificence and Dynamism on the Relationship between Discretionary Social Responsibility and Firm Performance”, Journal of Business Ethics, 49(1), 41-54.

Granovetter, M. (1973), "The Strength of Weak Ties", American Journal of Sociology, 78(6), 1360-1380.

Granovetter, M. (1983), "The Strength of Weak Ties: A Network Theory Revisited", Sociological Theory, 1(1), 201-233.

Gulati, R. ve diğerleri (2002), "Organizational networks", Joel A.C. Baum (Ed.), The Blackwell Companion to Organizations içinde (281-303), Oxford: Blackwell Publishers.

Hitt, M. A. ve diğerleri (1997), "International Diversification: Effects on Innovation and Firm Performance in Product-Diversified Firms", Academy of Management Journal, 40(4), 767-798.

Karaevli, A. (2008), "Türkiye'deki İşletme Gruplarında Çeşitlendirme Stratejilerinin Evrimi”, Yönetim Araştırmaları Dergisi, 8(1-2), 85-107.

Karahanna, E. ve Preston, D. S. (2013), "The Effect of Social Capital of the Relationship Between the CIO and Top Management Team on Firm Performance", Journal of Management Information Systems, 30(1), 15-56.

Koka, B. R. ve Prescott, J. E. (2002), "Strategic Alliances as Social Capital: A Multidimensional View", Strategic Management Journal, 23(9), 795-816.

Kozan, K. M. ve Akdeniz, L. (2014), "Role of Strong Versus Weak Networks in Small Business Growth in an Emerging Economy", Administrative Sciences, 4(1), 35-50.

Kraatz, M. S. (1998), "Learning by Association? Interorganizational Networks and Adaptation to Environmental Change", Academy of Management Journal, 41(6), 621-643.

Krackhardt, D. (1992), "The Strength of Strong Ties: The Importance of Philos in Organizations", Nohria Nitin ve Eccles Robert G. (Ed.), Networks and Organizations: Structure, Form and Action içinde (216-239), Boston: Harvard Business School Press.

Lee, J.-H. ve diğerleri (2012), “Outside Directors' Social Capital and Firm Performance: A Complex Network Approach”, Social Behavior and Personality: An International Journal, 40(8), 1319-1331.

Leff, N. H. (1978), "Industrial Organization and Entrepreneurship in the Developing Countries: The Economic Groups", Economic Development and Cultural Change, 26(4), 661-675. 
Li, Y. ve diğerleri (2011), “Organisational Learning, Product Quality and Performance: The Moderating Effect of Social Ties in Chinese Cross-Border Outsourcing", International Journal of Production Research, 49(1), 159-182.

Lin, N. ve diğerleri (1981), "Social Resources and Strength of Ties: Structural Factors in Occupational Status Attainment", American Sociological Review, 46(4), 393-405.

Lin, N. (1999), "Building a Network Theory of Social Capital", Connections, 22(1), 28-51.

Lin, N. (2005), A Network Theory of Social Capital, http://www.proclassic.com/ethnicgv/SN/SC/paper-final-041605.pdf (Erişim: 01.02.2015).

Lowik, S. ve diğerleri (2012), "Strong Ties as Sources of New Knowledge: How Small Firms Innovate through Bridging Capabilities", Journal of Small Business Management, 50(2), 239-256.

Mahmood, I.P. ve diğerleri (2011), "Where can Capabilities Come From? Network Ties and Capability Acquisition in Business Groups", Strategic Management Journal, 32(8), 820-848.

Malik, T. (2012). "Disparate Association Between Alliance Social Capital and the Global Pharmaceutical Firm's Performance", International Business Review, 21(6), 1017-1028.

Michelfelder, I. ve Kratzer, J. (2013), "Why and How Combining Strong and Weak Ties within a Single Interorganizational R\&D Collaboration Outperforms Other Collaboration Structures", Journal of Product Innovation Management, 30(6), 1159-1177.

Montgomery, C.A. (1982), "The Measurement of Firm Diversification: Some New Empirical Evidence”, Academy of Management Journal, 25(2), 299-307.

Obukhova, E. (2012), "Motivation vs. Relevance: Using Strong Ties to Find a Job in Urban China", Social Science Research, 41(3), 570-580.

Özgen, H. ve Özgen, H. M. (2009), "Neden Bazı İşletme Grupları Diğerlerinin Gerisinde Kalmaktadır? Türkiye'deki Bölgesel Şebeke Örgütleri Örneği’, Selçuk Üniversitesi Sosyal Bilimler Enstitüsü Dergisi, 22, 325-334.

Özkara, B. ve diğerleri (2008), “Türkiye'de İşletme Grupları: Eskiler ve Yeniler”, Yönetim Araştırmaları Dergisi, 8(1-2), 59-83.

Palepu, K. (1985), "Diversification Strategy, Profit Performance and the Entropy Measure”, Strategic Management Journal, 6(3), 239-255.

Perry-Smith, J. E. (2014), "Social Network Ties Beyond Nonredundancy: An Experimental Investigation of the Effect of Knowledge Content and Tie Strength on Creativity", Journal of Applied Psychology, 99(5), 831-846. 
Rost, K. (2011), "The Strength of Strong Ties in the Creation of Innovation", Research Policy, 40(4), 588-604.

Sambharya, R.B. (1995), "The Combined Effect of International Diversification and Product Diversification Strategies on the Performance of U.S.Based Multinational Corporations", Management International Review, 35(3), 197-218.

Sargut, S. A. (2006), "Sosyal Sermaye: Yapının Sunduğu Bir Olanak mı, Yoksa Bireyin Amaçlı Eylemi mi?”, Akdeniz Üniversitesi İ̈BF Dergisi, 6(12), 113.

Sözen, H. C. (2007), Bağlam Kapsamında Örgütler Arası Ă̆ Düzenekleri: Dayanıklı Ev Aletleri Sektörü Örneği, Yayınlanmamış Doktora Tezi, Başkent Üniversitesi Sosyal Bilimler Enstitüsü.

Sparrowe, R. T. ve diğerleri (2001), "Social Networks and the Performance of Individuals and Groups", Academy of Management Journal, 44(2), 316-325.

Şahin, K. T. ve Mert, K. (2014), “Türkiye'deki İşletme Gruplarının Uluslararasılaşma Motivasyonunun Lokasyon ve Giriş Stratejisi Üzerindeki Etkisi”, TISK Akademi, 9(18), 74-98.

Tiwana, A. (2008), "Do Bridging Ties Complement Strong Ties? An Empirical Examination of Alliance Ambidexterity", Strategic Management Journal, 29(3), 251-272.

Tomlinson, P. R. (2011), "Strong Ties, Substantive Embeddedness and Innovation: Exploring Differences in the Innovative Performance of Small and Medium-Sized Firms in UK Manufacturing", Knowledge and Process Management, 18(2), 95-108.

Tsai, W. (2001), "Knowledge Transfer in Intraorganizational Networks", Academy of Management Journal, 44(5), 996-1004.

Uzzi, B. (1996), "The Sources and Consequences of Embeddedness for the Economic Performance of Organizations: The Network Effect", American Sociological Review, 61(4), 674-698.

Uzzi, B. ve Lancaster, R. (2003), "Relational Embeddedness and Learning: The Case of Bank Loan Managers and Their Clients", Management Science, 49(4), 383-399.

http://www.kap.gov.tr/sirketler/islem-goren-sirketler/tum-sirketler.aspx (Erişim: 16.03.2014).

http://www.osha.gov/pls/imis/sicsearch.html (Erişim: 17.07.2014). 